\title{
A ÁFRICA NO CAPÍTULO XXXV DO ÉDITO DO MÁXIMO DE DIOCLECIANO'
}

Pascal Arnaud

Université de Nice-Sophia-Antipolis

O capítulo XXXV do Edictum de Pretiis rerum uenalium de Diocleciano² é inteiramente dedicado à tarifação do transporte marítimo e fluvial. Seu tronco comum consiste em uma lista de quarenta e nove relações marítimas. A despeito de sua importância teórica, esse texto foi relativamente pouco estudado, e por autores que não dispunham das mais recentes edições (GRASER 1940, pp. 166-173; MICHELL 1947, p. 7; ROUGÉ 1966, pp. 88-89 et 97-99; DUNCAN-JONES 1974). Esse fato explica as dificuldades inerentes à natureza do édito e as dúvidas que são colocadas, já há bastante tempo, quanto à sua pertinência e valor documental. Com muito bom senso, Elsa Rose Graser defendeu, no entanto, o principio segundo o qual, mesmo que aceitemos a ideia de artificialidade dos preços indicados no Édito (o que é inerente à própria natureza de um documento que não nos deixa a lista dos preços reais, mas somente os limites teóricos recomendados de não exceder), os serviços ou bens tarifados existiam e eram objetos de uma demanda real. A ideia de que deveriam possuir entre eles um princípio de proporcionalidade incita a retomar sua análise, buscando um método à origem dessa relação de dados (JONES, 1974, p. 351).

Dentro desta lista de rotas marítimas, a África é com Alexandria, o Leste, a Ásia, Roma, a Sicília, a Nicomédia e Bizâncio, um dos lugares aos quais era atribuído o privilégio de

\footnotetext{
${ }^{1}$ Texto traduzido com a autorização do autor. Publicação original : ARNAUD, Pascal. L'Afrique dans le chapitre XXXV de l'Édit du Maximum de Dioclétien. In: CANDAU MORÓN, José Maria; GONZÁLEZ PONCE, Francisco José; CHÁVEZ REINO, Antonio Luis (org.). Libyae Lustrare Extrema: Realidad y literatura en la visión grecorromana de África, Homenaje al prof. Jehan Desanges. Sevilha: Universidad de Sevilla, 2008, p. 127-144. Tradução: Felipe Alberto Dantas - Mestre em História. Universidade Paulo - São Paulo, SP, Brasil. e-mail: felipealbertodantas@hotmail.com

${ }^{2}$ As edições de refêrencia do capítulo são aquelas que deram M. Crawford e J. Reynolds da cópia de Aezani (CRAWFORD-REYNOLDS, 1979), depois por J. Reynolds daquela de Aphrodisias (REYNOLDS, 1989). Nós conservamos a numeração delas. As edições anteriores de S. Lauffer (LAUFFER, 1971) e de M. Giacchero (GIACCHERO, 1974) tornaram-se caducas para este capítulo e mais ainda para as adições de Aphrodisias.
} 
encabeçar tópicos, denominada a este título como origem de uma série de caminhos. $\mathrm{O}$ seu nome aparece não menos que onze vezes neste capítulo, junto com o Leste, ou logo atrás deste, se considerarmos, como é plausível, que Foenice (1. 44) é nominada como o sinônimo de Leste; e à frente de Alexandria, mencionada dez vezes, e de Roma e Nicomédia, citadas nove vezes nesse tronco comum.

Esta particularidade, não é simplesmente tão somente devido ao papel central que a África ocupa no seio do Império Romano Tardio. Ela nos conduz à interrogação sobre o papel da sua posição, na articulação entre dois sistemas meteorológicos e duas bacias de navegação, ligadas entre elas pelo canal da Sicília e pelo estreito de Messina. A África adquire, por isso, o valor de uma zona-teste, para se tentar entender a dinâmica e os princípios que presidiram a tarifação do transporte marítimo, e suas relações com a realidade das rotas de navegação.

Tivemos a ocasião, já duas vezes recentemente, de abrir este dossiê (Arnaud 2005, pp. 139-145; 2007). A justa homenagem que rendem hoje à J. Desanges seus colegas e amigos nos fornece a oportunidade de aprofundar a reflexão engajada, apoiando-nos num caso regional complexo.

\section{Objetivos e natureza do Édito: um estado da Historiografia}

Os objetivos, a pertinência e a eficácia do "Édito do Máximo", continuam como uma questão tão discutida quanto o valor documental desse texto complexo, alimentando numerosos debates. Ordinariamente admitimos, seguindo J. Lafaurie, que o documento teria sido promulgado entre 20 de novembro e 10 de dezembro de 301 (LAFAURIE1965, pp.197-198), mas essa datação não se sustenta sobre nenhum argumento sólido, e, de fato, o Édito teria sido promulgado no mesmo dia em que o Édito de Reforma Monetária, de 1 de setembro de 301 (CRAWFORD, 1975, p. 277). A escolha de uma ou outra data não é irrelevante, porque as duas teses se opõem quanto à interpretação do Édito: a dominante, defende a interpretação de um texto escrito e publicado às pressas, para limitar os efeitos nocivos sobre os preços, da reforma monetária, que é anterior a 1 de Setembro daquele ano; a outra interpretação, é a de um texto que, ao contrário, foi lentamente desenvolvido e amadurecido, como parte de um

projeto coerente, apoiado em dois decretos promulgados no mesmo dia. Também é discutivel o âmbito de aplicação geográfica do Édito.

Se acreditarmos nas palavras do preâmbulo, o Édito fixou-se o objetivo de pôr termo à auaritia, na qual reconhecia a principal razão para o aumento de preços. Essa apresentase não só como uma calamidade, mas também como uma fonte de desigualdade inaceitável entre as províncias. Ao definir um preço legal máximo para cerca de 1.300 
produtos, serviços ou benefícios, o documento transformava os tetrarcas em benfeitores universais. De acordo com a fraseologia comum nesse período, o Édito atribuía efetivamente um escopo universal ${ }^{3}$, da qual a realidade continua a ser muito discutida. Com exceção de uma cópia descoberta na Itália, os trinta exemplares conhecidos até hoje, vêm de quatro províncias sob a autoridade de Diocleciano. A origem exata do único fragmento encontrado fora desta zona (cópia de Pettorano sul Gizio), infelizmente é incerta. Enquanto para alguns a origem italiana do documento que por muito tempo, acreditou-se que fora gravado em mármore de Carrara continua a ser fora de dúvida (Guarducci 1985), para muitos outros, o fato de que ele tenha escrito em grego, de modo que nenhuma versão bilíngue é conhecida, também serve aí de indícios de que se trate de uma pedra transportada da Acaia (Bingen,1954, p. 349, n. 2; DOYLE, 1976, p 78; CRAWFORD, 1984).

O fato de que não se sabe até hoje de nenhuma cópia do Édito proveniente da província de Bitínia, onde Diocleciano tinha sua capital, mostra que a escolha das modalidades de exposição e as línguas do Édito, grego ou latim, parecem, portanto, terem sido deixadas a critério dos governadores de cada província. Gravar os textos oficiais em pedra é a norma no Oriente. No Ocidente, o costume era o de gravar, mais normalmente, em bronze, o que testemunha em favor dos defensores da origem grega do fragmento de Pettorano. A ausência de uma cópia conhecida vinda da província da Bitínia poderia ser explicada pela aplicação da prática italiana, na província onde o imperador tinha a sua residência. A atribuição à Acaia do fragmento de Pettorano não parece, portanto, opor-se à aplicação universal do Édito, mesmo que ela seja de fato, indemonstrável.

A fraseologia moralizante do preâmbulo do Édito e na exposição dos motivos que o justificava, sem dúvida, decorre de uma construção retórica e ideológica da qual não há nenhuma razão em particular para ser surpreender, como, em efeito, era de costume para a época (VAN SICKLE, 1932). Ela não afeta os resultados que seus autores esperavam para um decreto que deveria ser considerado com a maior seriedade, embora seu valor documental na história econômica está longe de ser evidente.

Entre os temas mais debatidos figura no topo, o da artificialidade dos preços do Édito. Muitos estudiosos (ERIM [et al.], 1971 COPE, 1977) pensaram que que o objetivo visado era evitar ou impedir a especulação e desordem causadas pela implementação de uma

${ }^{3}$ Cohortamur ergo omnium devotionem, ut res constituta ex commodo publico benignis obsequis et debita religione $<$ custodi $>$ atur, $m[a x]$ ime cum $e<i u>s$ modi statuto non civitatibus singulis ac populis adque provinciis, sed universo orbi provisum esse videatur, in cuius pe[rnici]em pauci atmodum desaebisse noscantur, quorum avaritiam nec prol<i>xitas temporum nec divitiae, quibus studuisse cernuntur, m[iti]gareaut satiare potuerunt. 
reforma que, dobrando o valor de face do argenteus, dividida por dois o valor desse último (HENDY, 1985 pp. 451-457). O preâmbulo se refere a preços que subiram 4, 8 ou mais vezes, o valor normal de alguns bens 4 . $\mathrm{O}$ medo da insolvência do contribuintes privar o Tesouro de parte de suas entradas teriam levado Diocleciano e sua administração a desenvolverem apressadamente um édito improvisado para limitar este fenómeno.

Alguns estudiosos, fundados no depoimento notoriamente hostil de Lactâncio, acreditam que os preços máximos permitidos pelo Édito, quando de sua promulgação, abaixo do mercado ou aberrante (JONES, 1953, p. 299) e sublinham bastante a artificialidade dos preços que ele menciona (JONES, 1974, p. 351; CRAWFORD, 1975). Pode ser tentador colocar essas características na conta da improvisação de um édito que deu errado. A análise mais apurada da realidade dos preços, na verdade, ilustra que, de acordo com o texto do preâmbulo, eles variavam muito de uma região para outra, e aqueles que aparecem no texto estavam, de fato, superiores ao fixado pela norma, especialmente nas províncias orientais. Apenas aqueles da capital se assemelhavam aos encontrados no Édito (SPERBER, 1974 pp. 115-130). Dado o ritmo da inflação, é necessário manter a cautela, mas essa análise tem o mérito de concordar com os objetivos fixados no Édito do máximo: reduzir as disparidades e limitar a especulação, definindo tetos legais, um ponto enfatizado por J.-P. Callu (CALLU, 1969, p. 405). Sem dúvida, este texto foi vítima junto aos estudiosos, seja por se mostrar ineficaz no médio prazo, seja pela visão preconceituosa que atribui-se ao pensamento econômico dos Antigos. Há todas as razões para acreditar que, no momento da sua promulgação, ele foi provavelmente o que ele pretendia ser e que realmente fixava os preços acima do verificados na prática, e, portanto, artificial na natureza. É a incapacidade da reforma monetária para conter a inflação, que fez o Édito o objeto amaldiçoado descrito por Lactâncio, e que parece ter justificado a destruição metódica de suas cópias.

Mais do que uma solução encontrada em uma emergência, o decreto parece se integrar na tentativa de uma reforma global da sociedade, por iniciativa dos novos parentes generis humani. Uma análise cuidadosa da política dos tetrarcas (CORCORAN 1996, pp. 215-245) levou a uma reavaliação do Édito, que resultaria de uma longa gestação, e teria sido amadurecido em Antioquia, durante a Guerra Persa de Diocleciano ${ }^{5}$. A ideia de que os preços poderiam ser os mesmos de uma extremidade à outra de um império

\footnotetext{
${ }^{4}$ Pretia venalium rerum non quadruplo aut oct [uplo, sed i] ta extorquere, utnomina $<a>$ estim $<$ ati $>$ onis et facti explicare humanae linguae ratio non possit.

${ }^{5}$ Cf. Pap. Antin. , i 38, do 13 abril, 301,que teria colocado em prática uma medida preparatória ao Édito do Maximum (CRAWFORD, 1975, p. 277).
} 
livre da uaritia procedia de uma atitude, sem dúvidas, mais reveladora de uma pretensão ideológica de harmonia universal e felicidade que de realidades econômicas. O decreto pregava introduzir uma revolução salutar. Como reconhece A.H.M. Jones:

"the general scale of prices was arbitrary, but there is no reason to believe that the relation of one price to another was distorted" (Jones 1974, 351 p.). É difícil imaginar que a tarefa gigantesca de estabelecer uma lista de preços para mais de mil artigos, salários e serviços, conservando um mínimo de coerência interna, mesmo que não em contato direto com os preços real, tenha sido objeto de uma improvisação total. Estamos então fundados a nos interrogar sobre os princípios e métodos que levaram ao desenvolvimento e cálculo de preços-tetos legais. Estamos ainda mais inclinados a considerar seriamente este decreto que fixava como castigo para a sua violação a pena capital e, como veremos, no capítulo XXXV do Édito - o que vai nos interessar diretamente aqui - foi objeto de adições, retoques e precisões, mas ao nosso conhecimento, sem correções, e que estava ainda em vigor em 310, talvez, se é que podemos deduzir isso da gravação do nome de Maximiano na cópia de Ptolemaida (CRAWFORD 1975, p. 277).

\section{O capítulo XXXV}

O capítulo final do Édito (XXXV), intitulado ex quibus loci ad quas provincias quantum nauli excedere mínima sit licitum é inteiramente dedicado à tarifação do naulum, ou seja, do transporte marítimo, concebido como um serviço de aluguel de um volume de casco para um determinado destino. Do ponto de vista retórico, é uma espécie de eco do preâmbulo, que apresenta o decreto como benfeitoria (évergésie) universal própria à restauração da paz. Ele nos dá a imagem pacífica de uma prosperidade e paz reencontradas, e de um império reunido, percorrido agora sem dificuldades por navios de comércio que negociam desde o Atlântico até o Cáucaso, e ao mesmo tempo, com uma visão otimista da continuidade e dos preços da cadeia de abastecimento, estreitamente associados ao aumento dos preços que o Édito pretendia regular.

Ele faz um balanço das quarenta e sete rotas marítimas que formam o primeiro estado de publicação do Édito. O texto correspondente deste relatório está completo. Ele é conhecido por duas versões latinas de Aezani e Aphrodisias (CRAWFORDREYNOLDS, 1979; REYNOLDS, 1989), parcialmente completadas por fragmentos gregos dos manuscritos de Delfos e Tégea. Possuímos também extensos fragmentos de acréscimos posteriores a esse tronco comum, conhecidos pelo manuscrito único de Aphrodisias, sob a forma de uma outra lista, adicionada no fim do decreto. 
Sabe-se agora que houve pelo menos duas versões deste capítulo. Em um primeiro estado, o decreto terminava após a versão curta do Capítulo XXXV, cujo texto é comum a Aezani e Aphrodisias. Uma cópia do Aezani acompanha a carta de Fulvius Asticus (CRAWFORD-REYNOLDS, 1979), e a presença em Aphrodisias de uma fórmula conclusiva após a 1.56 deixa pouca dúvida de que o édito não parou por aí inicialmente (REYNOLDS 1989, p. 36).

Adições, de extensão difícil de mesurar foram praticadas em dois manuscritos: em Aezani, a carta de Fulvius Asticus é seguida por uma coluna mutilada que parece corresponder ao texto da Aphrodisias IX. 51 s. (ou seja, uma parte do cap. VI). O manuscrito Aphrodisias, por sua parte, manteve seis fragmentos de ordenamento complexo que se relacionam todos com o conteúdo do capítulo XXXV e que J. Reynolds os agrupou sob o rótulo de capítulo XXXV A. Um primeiro grupo de fragmentos (XXXV A I e II) retoma a lista original, estendendo-a, mas sem alterar sua ordem global: adiciona novas destinações ${ }^{6}$, a tarifação do transporte lacustre e fluvial é refinada, e a menção praeter onera fiscalia quae formam suam optinent é adicionada à todas as referências a Roma. O custo das relações já presentes no Capítulo XXXV não é reavaliada. Um segundo grupo de fragmentos (IV e V) é caracterizado pela presença recorrente da fórmula de tributação quae species praeter formam suam optinent, que poderia ter relação com partidas originárias de Roma. A fórmula não é a que aparece no fragmento I e pode se relacionar com outra série de acréscimos. Finalmente, os fragmentos III e VI, muito mutilados, fornecem listas de lugares e preços irredutíveis com outras sequências conhecidas.

A existência destas adições sugere que não só o texto foi levado muito a sério por seus autores, mas também que os preços fixados nele pareciam relevantes o suficiente para não terem sido mudados. Apesar da característica globalmente artificial, enfatizada repetidamente, os preços que encontramos em vários capítulos, e, mais especificamente no capítulo XXXV, no qual estamos interessados, aos olhos dos autores tinham um valor efetivo suficiente o bastante para justificar precisões e acréscimos, mas nenhum remorso quanto à adequação do preço.

\footnotetext{
${ }^{6}$ Essas adições são: uma rota da Sicília a Genua (XXXV A I, 1. 3), cujo nome estava ausente do cap XXXV, tomando lugar após a rota Sicília-Gálias (XXXV 37); ela é imediatamente seguida por quatro rotas partindo da Sardenha (XXXV A I, II. 4-8): em direção à Roma, um lugar desconhecido, Gênova e $s[---]$, cujo qual o nome não aparecia no cap. XXXV; depois duas rotas em direção à Roma (XXXV A I, II, 9-12) a partir de lugares desconhecidos. Encontramos, em seguida, a ordem do cap. XXXV, mas entre XXXV 42 e 43 foi inserida uma rota A Nicomedia [+++++++]am. Os fragmentos que compõem XXXV A II retomam os II. 12-24 do cap. XXXV sem modificação, exceto a precisão Hispaniam Terraconensem no lugar de Ispaniam (sic); após as seis linhas que seguem, mutiladas, introduzem montantes irredutíveis à sequências conhecidas e uma menção que parece relativa à óleo. Não sabemos se esse fragmento deve ser reportado à mesma lista que I ou se ele deve ser reportado mais à IV e V.
} 
A estrutura do núcleo do capítulo é extremamente interessante. Recentemente, tivemos a oportunidade de nos deter sobre isso (ARNAUD, 2007) e daremos aqui a síntese desses resultados. De fato, o capítulo se apresenta como uma lista de rotas enumeradas a partir de uma série de oito pontos de partida, cujos nomes aparecem na ordem seguinte, no texto latino:

Alexandria
Oriens
Asia
Africa
Roma
Sicilia
Nicomedia
Byzantium

Essa ordem, geograficamente aberrante, à primeira vista, parece desprovida de qualquer lógica. No entanto, transcrita em grego a sequência se torna:

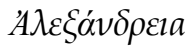

$$
\begin{aligned}
& \text { Avatoגí } \\
& A \sigma^{\prime} a
\end{aligned}
$$

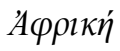

$$
\begin{aligned}
& \text { Pópi } \\
& \text { ¿ikel'a }
\end{aligned}
$$

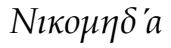

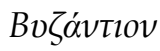

Ou seja, até a menção à Sicília, a ordem é a alfabética grega. A escolha de uma ordem alfabética não é de surpreender. É a mesma que adota numerosos documentos utilizados pela administração romana, e notadamente, aqueles que temos o costume a reconhecer como formulae prouinciarum (CUNTZ, 1888; DETLEFSEN, 1908; CHRISTOL, 1994). A partir disso, podemos fazer já duas constatações: de uma parte, o Édito, gravado em latim mesmo em cidades gregas do oriente, remonta na realidade a um original redigido em grego. De outra parte, existe nessa ordem alfabética duas 
exceções, colocadas no fim: Nicomédia e Bizâncio. Nas adições de Aphrodisias (XXV A), a Sardenha foi inserida após a Sicília, sem dúvidas em nome da coerência em relação ao posicionamento das ilhas na descrição. Ressaltamos, aliás, que na rúbrica relativa às rotas originárias de Alexandria, Nicomédia e Bizâncio, elas (Sicília e Sardenha) aparecem na mesma ordem que na lista geral, logo depois de Roma, que ocupa em sua qualidade de capital do Império o primeiro lugar de cada rubrica. Nicomédia e Bizâncio aparecem assim como adições. A Nicomédia foi inserida somente na primeira nota introdutória, com um objetivo ideológico: associar a residência de Diocleciano à capital do Império. A ausência dessa cidade nas outras listas mostra que, ou todas as menções à Nicomédia foram ajuntadas à lista inicial, ou a lista inicial foi reorganizada, para dar à Nicomédia uma distinção especial.

As relações já mencionadas a partir de um ponto de origem determinado não são retomadas quando a destinação se torna a cabeça de tópico: Por exemplo, as relações Alexandria-África, Oriente-África, Ásia-África não são retomadas na lista de relações Ab Africa. O conteúdo das rubricas diminui então, ao fim e ao cabo progredimos na ordem alfabética. Concretamente, isso significa que não existia diferenciação na tarifação entre as viagens praticadas em um ou outro sentido, enquanto maioria das relações impunham às idas e voltas itinerários diferentes.

Algumas destinações são mencionadas somente a partir de pontos de origem determinados. As províncias ibéricas são mencionadas somente a partir do Oriente, da África e de Roma, e são detalhadas somente nas partidas do Oriente (Spaniam, Baeticam, Lysitaniam).

A informação maior que nos dá a estrutura enunciativa parece então ser que o texto publicado em 301 se apoia sobre um texto grego mais antigo, que não comportava a Nicomédia nem Bizâncio. Podemos hesitar sobre as conclusões cronológicas que tiramos desse dado. Ou nos fixamos ao valor simbólico da Nicomédia, lugar da proclamação de Diocleciano por suas tropas, em 20 de novembro de 284, e, a este título, lugar de celebração das Decennalia e das Vicennalia, e assim temos que considerar o texto de referência anterior à Diocleciano; ou consideramos que a residência do imperador é a única visada. $\mathrm{O}$ texto de origem seria então, simplesmente anterior ao retorno daquele a esta cidade, em 301. O corpo principal do texto teria sido redigido entre 297 e 301, no Egito ou na Síria, e completado pela introdução de Nicomédia e Bizâncio em 301. Ressaltamos, no entanto, que a Nicomédia estava ausente na rubrica Ab Oriente. Essa lacuna é coberta na rubrica A Nicomedia, mas a designação Oriens, de uso no início da lista, cedeu lugar à designação Foenice (1. 44), conforme inclusive à ortografia, ao conteúdo da lista de Verona. Nós somos então, tentados de reconhecer na lista original um modelo anterior a Diocleciano. 
A toponímia regional pode confirmar em parte esse julgamento. De fato, constatamos que os topônimos utilizados são de duas ordens: nomes de cidades (Alexandria, Roma, Nicomedia, Byzantium, Aquileia, Ephesus, Thessalonica, Salona, Trapezus, Amastris, Sinope, Tomi, por ordem de aparecimento ${ }^{7}$ ) ou nomes de regiões (Achaia, Asia, Africa, Baetica, Dalmatia, Foenice, Galliae, Lysitania, Oriens, Pamfylia, Sicilia, Spania $\left.{ }^{8}\right)$. Nessa lista aparecem nomes que são conhecidos também por serem de dioceses saídas das reformas de Diocleciano: é o caso da África, do Oriente e das Gálias. Mas se tratava certamente de nomes de diocese? Uma comparação com a lista de Verona nos mostra que não. Encontramos as Gálias no lugar que deveria aparecer a antiga Narbonense, em que deveríamos encontrar diocesis Viennensis; Alexandria, que ultrapassava a diocesis Orientis, e considerada como uma entidade distinta do Oriente, que aparecia indicar aqui, os portos do Levante.

Em detalhe, as regiões de extensão mais reduzida portam nomes de províncias conhecidas na reforma de Diocleciano, mas certas ausências são marcantes: são assim mencionadas na Espanha as três províncias do Alto-Império, mas não novas províncias criadas por Diocleciano nessa diocese, como notadamente a Karthaginiensis, que deveria ser mencionada entre a Espanha, como em XXXV A II, 1.4 em que a Terraconense e a Bética são explicitamente designadas. A âncora desse documento numa realidade anterior a Diocleciano parece pois, verossímil, e poderia se inscrever no duplo contexto do conservadorismo ambiente próprio à obra legislativa de Diocleciano (VAN SICKLE, 1932) e de um édito longamente amadurecido, conforme a opinião de S. J. Corcoran.

\section{“A África" no Édito}

No decorrer do capítulo XXXV, a África aparece como destinação em cada um dos das três rubricas que precedem a rubrica $A b A$ frica, e, em seguida, aparece na rubrica $A$ Nicomedia.

6 _ Ab Alexandria Africam in $k$ (astrensi) $m$ (odio) uno $¥$ decem.

14 _ Ab Oriente ad Africam in $k$ (astrensi) $m$ (odio) uno X sedecim.

23 _ Ab Asia ad Africam in $k$ (astrensi) $m$ (odio) uno ※ octo.

${ }^{7}$ XXXV A adiciona à lista Genua.

${ }^{8}$ Var.: Ispaniam (XXXV 15); Hispaniam Tarraconensem (XXXV A II, 1. 4). XXXV A adiciona à lista Sardinia. 
45 _ A Nicomedia in Africam in k(astrensi) m(odio) uno X quattuordecim.

Ela aparece em seguida como ponto de partida de seis relações:

26 _ Ab Africam Salonam in $k$ (astrensi) m(odio) uno X decem et octo.

27 _ Ab Africa in Sicilia in $k$ (astrensi) m(odio) uno X sex.

28 _ Ab Africa ad Spaniam in k(astrensi) m(odio) uno Xocto.

29 _ Ab Africa ad Gallias in k(astrensi) m(odio) uno Х quattuor.

30 _ Ab Africa ad Achaiam in k(astrensi) in m(odio) uno $¥$ duodecim.

31 _ Ab Africa ad Pamfyliam in k(astrensi) m(odio) uno X quattuordecim.

Precisamos adicionar, à 1. 25, a cabeça de rubrica (Item ab Africa Roman) com menção da relação entre a África e Roma: a cópia de Afrodisias não contém, curiosamente, nenhum montante, embora a peça seja completa. O fim da linha sendo mutilada na cópia de Aezani, deixa impossível de determinar com certeza se trata-se de uma particularidade do Édito, como pensa J. Reynolds (REYNOLDS, 1989, p.305), ou de um simples erro, próprio a cópia de Afrodisias, que cometeu outros no mesmo capitulo9, mais uma vez a propósito de uma cabeça de rubrica mencionando uma relação à destinação de Roma.

Nós pensamos, entretanto, que convêm supor ao fim da 1. 25 Item Ab Africa Roman <in $k$ (astrensi) m(odio) uno $X$ duodecim $>$. Não somentte esse montante é o que se encontra no final da 1. 24, o que explicaria facilmente o erro, mas ele também é igual à soma de dois dados já conhecidos: 6 denários da África na Sicília (1. 27) e 6 denários de Roma na Sicília (1 .32). Contudo numerosos preços foram obtidos pela soma de duas rotas distintas.

Não mais que na rubrica Oriens, o édito não distingue portos na nomeação genérica de África, única usada no texto. Esta nomeação é muito pouca clara. Podemos propor várias interpretações, a partir da escolha de reconhecimento um porto de predileção ao qual se identificaria a Africa - por exemplo Cartago -, antiga província da Africa

\footnotetext{
${ }^{9}$ A 1.46 da cópia de Aezani (Item a Byzant[i]o [Romam]) foi esquecida pelo lapicida (gravador). Esta rota aparece, no entanto, nas adições de Aphrodisias, XXXV A I, 11. 20-21: [Ite]m a Byzant [io Rom]am in $k$ (astrensi) $m$ (odio) uno $X$ decem et octo /[pr]aeter o[ne]ra f[iscalia quae formam suam optinent]. Ela permite completar o custo da relação, que não figurava na cópia de Aezani. $O$ custo que constava no final da 1.46 do ch. XXXV era idêntico àquele que era escrito na linha seguinte, e que começava pelas mesmas palavras. Isto explica provavelmente o erro.
} 
Proconsularis, ou a nova província de Proconsularis, de extensão mais reduzida, criada por Dioclétien entre 290 e 294 (DI VITA-EVRARD, 1984), a Diocesis Africae, ou ainda, simplesmente, uma expressão geográfica irredutível a um corte administrativo em sentido estrito, que poderia ser uma correspondente do Grego $\Lambda$ ıv́n . A ação de designar a África genericamente não é o própria do Edito. Chegamos "na África", como chegamos "na América", ao termo de uma percepção subjetiva do viajante que fez um travessia direta entre dois continentes. De Políbio à Estrabão (STR., II 4, 3,; II 5, 8), as distancias são dadas entre Narbona "na Líbia". Ainda é o caso quatro séculos mais tarde para Sulpício-Severo (Dial. I, 3) que fazia chegar Postumiano, saído de Narbona "de um porto da África" cuja a única certeza é de que não se tratava de Cartago $^{10}$. A África pode assim ser revestida de significações muito diferentes para viajantes chegando do oeste ou do norte, ou para uma pessoa se percebendo "africana". Essa subjetividade complexa, que define igualmente a noção de Oriens, sem dúvidas contribuiu para a disfarçar os limites exatos dessas noções, em proveito de designações regionais genéricas mantidas pelo uso.

Sabemos também que o Édito expressa, em suas várias versões, destinos ou pontos de partida, nomeando às vezes explicitamente um porto (Alexandria, Nicomédia, Éfeso, Salônia, Gênova, Aquileia, Tessalônica, Bizâncio, Tomes (Constância), Amastris (Amasra), Sinop, Trebizonda), outras vezes com referência a uma região inteira (África, Ásia, Oriente, Fenícia, Sicília, Sardenha, Espanha [Tarraconense, Bética, Lusitânia], Acaia, Panfília, Gália, Dalmácia).

A menção de portos não apresenta nenhum problema em si. A colocação de regiões comporta vários.

Primeiramente a questão de saber qual espaço é potencialmente designado por esses nomes. É obviamente tentador de reconhecer as divisões sendo as divisões administrativas das reformas de Diocleciano. Já vimos acima, as razões pelas quais nós somos levados a reconhecer por trás dos topónimos regionais de designações irredutíveis às divisões administrativas estritas, a fortiori àqueles de Diocleciano, exceto, talvez, para a menção das três províncias espanholas anteriores de Diocleciano, e a introdução de Foenice em vez de Oriens. A maioria dos nomes das regiões parecem mais constituírem designações de uso de que dados graváveis em um espaço

\footnotetext{
${ }^{10}$ Contrariamente a opinião bem disseminada (CASSON 1971, p.286, n.69), nada indica que este ponto tenha sido a Útica. Pelo contrário, podemos apostar que um nome tão famoso enquanto o de Útica tenha sido pronunciado no lugar anônimo de Portus Africae, que apenas o texto menciona.
} 
estritamente administrativo. A partir do Alto Empério, o nome étnico de Dalmata ou o topônimo Dalmatia parece ter sido um uso natural. A Panfília em vez de Lycia-Panfília, é certamente uma província saídas das reformas de Diocleciano, mas também é um espaço marítimo coerente, embora bem distinto de Lycia e tratado como tal pelos geógrafos e viajantes.

Quando os nomes são baseados em entidades administrativas, é aparentemente mais sobre aquelas do alto império do que aquelas de Diocleciano. Tudo isto concorda também muito bem com uma lista tributária de um documento anterior a Diocleciano.

Um segundo problema é de saber se essas regiões são reduzidas a um porto principal que designaria implicitamente ou por metonímia, ou se elas devem realmente ser consideradas como espaços. E. R Graser (GRASER 1940, p.169) deixou a porta aberta às duas interpretações. Sem dúvida, ela estava certa.

Se observamos a progressão dos valores de dados a partir de um único ponto de origem, como no caso de Alexandria e do Oriente, com destinação à Dalmácia (1. 4) e Salônia (1. 12) de uma parte, e de Aquileia (11. 5 e 13) de uma outra, aparece claramente que o custo adicional para a viagem de Salônia e da Dalmácia para Aquileia se elevam igualmente a 6 denários. Salônia e Dalmácia são aqui claramente sinônimos. Se voltamos agora para a Ásia, é claro que a relação de Nicomédia em África (L.45: 14 denários) é igual à soma das duas viagens da Ásia para a África (L. 23: 8 denários) e de Nicomédia para Éfeso (L.39: 6 denários). Parece assim que para os autores do édito, Éfeso e a Ásia formavam uma única realidade. Da mesma forma, a tarifa proporcionalmente muito elevada da relação entre a África e a Sicília (L.27: 6 denários) só pode ser entendida considerando que sob a designação genérica de Sicília, apenas os portos da costa oriental, Messina, Catania ou, mais provavelmente, somente Siracuse, foram considerados.

No entanto, pode ser questionada tanto a possibilidade de que realmente tivessem em mente regiões inteiras e na pertinência das equivalências assim praticadas pelos autores do Édito entre um porto e uma região. O Édito nos dá um exemplo quando ele agrupa toda uma série de pontos, às vezes distantes, em uma mesma rubrica e para um custo idêntico. Tal é o caso da rota chamada A Byzantio Amastris et Sinope Tomis (1. 49 Aezani $=48 / 48^{a}$ Aphrodisias), no valor avaliado a oito denários. Da mesma forma, no Stadiasme, os portos do Levante, embora sendo distinguidos uns dos outros são todos considerados situados à mesma distância de Rodes (§ 272 Müller).

Logo veremos que a rota que serviu de referência para a avaliação do custo da relação entre a África e a Gália chegava muito a oeste de Cartago, e que aquela que serviu ao cálculo do custo da viagem da Ásia para a África, provavelmente chegava a leste do Cap-Bon. As rotas de referência nos levam a considerar que sob a designação 
comum de África, na verdade, designa-se lugares muito diversos, localizados de ambos os lados do canal da Sicília, cuj a travessia do leste a oeste, contra os ventos predominantes, não é uma tarefa fácil. A maneira a qual os autores do Édito fizeram a tarifação das rotas somando os valores dos segmentos nos leva, porém, a admitir que eles trataram a África como um ponto e não como um espaço, ao contrário do que parece que fizeram para a Ásia.

\section{As Modalidades de Tarifação do Custo das Relações}

O Édito foi capaz de estimar o custo por milhas do transporte terrestre (cap. XVII: De vecturarum mercedibus), mas também e especialmente do transporte fluvial, cujos custos são fixados ao final do mesmo capítulo XXXV e foram revisados no final da adição XXXV A I de Aphrodisias. A escolha, desde o título do capítulo, de não adotar uma tarifação linear em relação a distâncias mostra claramente que as distâncias marítimas, nas grandes rotas relativamente consensuais (ARNAUD 1993; 2005, pp. 6196) não eram o objeto destas tarifas, e que cada relação era um objeto particular. $O$ objeto tarifado é o modius kastrensis, igual a 1,5 modius itálico (DUNCAN-JONES 1996), e de dois artabes. Embora esta unidade tivesse sido usada no édito para a medição de grãos (cap.1), ela não indica aqui um transporte especificamente relacionado com cereais. Se trata do bushel (modius kastrensis, modius, artabe ou medimnus) utilizado, de acordo com o uso, como unidade de referência de tonelagem dos navios (WALLINGA 1964). É precisamente o volume de carena, alugado ao "nauclère" pelo fretador que é o objeto do naulum (Dig. XIV 2,10), a que é dedicado o capítulo XXXV.

Por razões de simplificação, as últimas linhas do capítulo (1l. 50s) estabelecem o valor em modii kastrenses dos seres vivos ${ }^{11}$ assim graváveis em uma unidade de medida. Mais uma vez o objetivo de unificar caraterístico do Édito aparece de maneira óbvia. O uso de modius kastrensis é mais original, mesmo se a unidade é ocasionalmente utilizada em algumas outras passagens. Se não se trata de nenhuma influência das práticas de propaganda militar, poderia se tratar de uma simples facilidade de conta.

Ficamos impressionados com a similitude dos valores em denários, formulados pelo édito, e os tempos de viagens conhecidos por um certo número dessas relações, a ponto de sermos levados a formular a hipótese de que os valores em denários poderiam ser a transcrição pura e simples dos tempos das viagens registrados pela

${ }^{11}$ Homen (25 m.k), cavalo, mula, Bardoto, boi et burro (60 m.k), Ovelha, cabra e porco (10 m.k) 
memória coletiva (ARNAUD 2005, pp. 139-145; 2007). Por um efeito da reforma monetária e da falta de unidade a inferior a dois denários, os preços parecem terem sido sistematicamente arredondados ao denário inferior.

Podemos resumir essas semelhanças na tabela da página seguinte. É particularmente notável que alguns dos mais surpreendentes dados do édito, em particular os montantes de 4 e 6 denários que são respectivamente a tarifa do bushel dos campos entre a África e a Gália e entre a África e a Sicília, e encontram seu lugar nesta tabela. Não é menos notável que eles se entendam apenas por referência a tempos de percurso gravados na direção oposta do que é afirmado no decreto, e que os custos sejam reversíveis e indiferentes à direção de viagem.

O período de 4 dias entre a Gália e a África, que é o da viagem de Postumiano entre Narbona e a África (SULP. SEV., Dial I, 3) é de fato um dado amplamente consensual que fundou sobre a experiência dos marinheiros a avaliação dos geógrafos da distância entra a Gália/ As Gálias e a África (ARNAUD 2005, pp.153-157): cinco dias e cinco noite eram considerada a rota mais longa de Europa e a Líbia, a partir do fundo do Golfo Galático (STR., II 5, 8). O ponto de chegada na África é geralmente localizado bem a oeste (Golfo de Bejaïa [Bugia]), o que poderia constituir uma indicação do valor muito amplo de termo África no édito. Em revanche, aplicar este valor para a rota de retorno, dificilmente viável em uma linha reta, é uma especulação. Da mesma forma, o custo proporcionalmente muito alto aplicado ao itinerário África-Sicília tem como sentido sentido apenas aquele entre a costa oriental da ilha e o Cap-Bon, onde ele se efetua em toda a estação contra ventos e correntes, no canal de Malta. A rota mais natural de Siracusa para Cartago é aquela sugerida pela ordem de enumeração das ilhas ao sul da Sicília, em Diodoro da Sicília (V12), e que foi seguida em parte pela frota de Belisário (PRO-COP., Vand. I14), de Siracuse a Malta e Gozzo, e de lá por Lampedusa até Caput-Vada (Ras Kapudia), depois de um dia inteiro de navegação. Desde Kerkennah, ela seguia a costa até o Cab-Bon, que se confunde parcialmente com a rota de Selinunte, seguida desde Cirene pelas muralhas peloponesianas, em 413413 (TH., VII 50, 2). Ela evitava os ventos e correntes contrários do canal da Sicília e utilizava os fluxos de sudeste característicos das costas orientais da Tunísia. A identidade dos custos entre a Sicília e a África a partir do Leste se explica, sem dúvidas, pelo uso comum para as duas destinações, totais ou parciais (até Leptis ou as Kerkennah) do mesmo itinerário. Estes dois exemplos são suficientes para demonstrar que as rotas não foram estimadas na base da hipótese mais otimista, mesmo que isso parecesse ter sido normalmente a norma.

Revista Heródoto. Unifesp. Guarulhos, v. 01, n. 01. Março, 2016. p. 438-457. 


\begin{tabular}{|c|c|c|c|c|}
\hline Rota & $\begin{array}{l}\text { Preço em } \\
\text { denários }\end{array}$ & $\begin{array}{l}\text { Duração } \\
\text { conhecida }\end{array}$ & Fonte & Notas \\
\hline $\begin{array}{l}\text { África - Acaia } \\
\text { África - Sicília } \\
+ \\
\text { Sicília - Acaia }\end{array}$ & $\begin{array}{l}12 \\
6\end{array}$ & $\begin{array}{l}? \\
6\end{array}$ & $\begin{array}{l}\text { D.S., XX 6,1-2 } \\
\text { PHILOSTR., VA VIII } \\
15\end{array}$ & $\begin{array}{l}\text { Siracusa-Cap- } \\
\text { Bon (Cassion, } \\
\text { 1971, p. 295, n. } \\
\text { 108) } \\
\text { Siracusa-Alfeu }\end{array}$ \\
\hline África - Gálias & 4 & $\begin{array}{l}4 \\
5 \\
5,5\end{array}$ & $\begin{array}{l}\text { SULP.SEV., } \\
\text { Dial.I3 } \\
\text { STR.II 4, } 3 \\
\text { Geog. Compend., } 40 \\
\text { (Müller, GGM } \\
\text { II,p.105) }\end{array}$ & $\begin{array}{l}\text { De Narbona em } \\
\text { África ou de } \\
\text { Marselha à } \\
\text { Igilgili (Djidjelli) }\end{array}$ \\
\hline Oriente - Roma & 18 & 18 & VITA Melan. Iunior. & $\begin{array}{l}20 \text { dias (dos } \\
\text { quais uma escala } \\
\text { de } 2 \text { dias para } \\
\text { visitar um amigo } \\
\text { à Nola }\end{array}$ \\
\hline Oriente - Bizâncio & 12 & 12 & $\begin{array}{l}\text { MARC. DIAC., } V . \\
\text { Porph. } \\
55\end{array}$ & $\begin{array}{lr}\text { De Bizancio; } 10 \\
\text { dias também } \\
\text { atestados } \\
\text { Bizâncio, desde }^{13} \text { e } 20 \\
\text { dias } \\
\text { Gaza14 }\end{array}$ \\
\hline $\begin{array}{l}\text { Alexandria - África } \\
\text { Alexandria - Phicus } \\
\text { Leptis Magna - Ben Ghazi }\end{array}$ & 10 & $\begin{array}{l}6 \\
3\end{array}$ & $\begin{array}{l}\text { SYNES., Ep. } 51 \\
\text { PLIN., Nat. V 31; } \\
\text { PS.. } \\
\text { SCYL., Per. } 109\end{array}$ & \\
\hline $\begin{array}{l}\text { Alexandria - Panfília } \\
\text { Ilhas Caledonianas - } \\
\text { Canope }\end{array}$ & 6 & 4 & STR., XIV 3, 7 & $\begin{array}{l}\text { Adicionar } 1 \text { dia } \\
\text { até a Panfília }\end{array}$ \\
\hline $\begin{array}{l}\text { Alexandria - Cap Acamas } \\
\text { de Chipre }\end{array}$ & & 6 & LUC., Nau. 7 & $\begin{array}{l}\text { Adicionar } 1 \text { dia } \\
\text { até a Panfília }\end{array}$ \\
\hline $\begin{array}{l}\text { Alexandria - Tessalônica } \\
\text { Ascalon - Tessalônica }\end{array}$ & 12 & $13 / 12$ & $\begin{array}{l}\text { MARC. DIAC., V. } \\
\text { Porph. } 6\end{array}$ & $\begin{array}{l}13 \text { dias de ida, } 12 \\
\text { de retorno }\end{array}$ \\
\hline
\end{tabular}

12 Ptolomeu (Georg., II 10, 8; IV 2,11) local 11 ${ }^{\circ}$, ou seja, 5.500 estádios, entre Marselha e Djidjelli.

${ }^{13}$ MARC. DIAC., V. Porph. 55: a destinação era Gaza nos dois casos.

${ }^{14}$ MARC. DIAC., V. Porph. 26 (Gaza-Byzance); Ibid. ,35.37 (10 dias de Césareia à Rodes, e o mesmo tanto dali à Bizâncio). 
A indiferença absoluta dos autores do édito em relação à direção das rotas não deixa de ser um dos elementos mais surpreendentes deste édito. É claro que um número significativo de retornos eram feitos seja por vias diferentes seja com condições de ventos normalmente muito diferentes. Eles se distanciam aparentemente da realidade das rotas marítimas, mas sua indiferença com a direção das rotas é sem dúvida um efeito da estrutura pendular das trocas de longa distância, que é a qual emerge da estrutura do empréstimo para grandes aventuras (ARNAUD 2005, pp.114-117). Temos a sensação, inclusive, de que eles procuraram evitar, por simplificação, uma lista interminável, e encontrar um princípio tanto incontestável quanto vantajoso. Incontestável, uma vez que se baseava em dados validados por vários séculos de memória de navegação no Mediterrâneo e na sua "normalidade". Vantajoso, uma vez que tomava, em regra geral, como base não apenas as opções geralmente mais favoráveis, mas ainda rotas não segmentadas ou resultantes da simples adição de segmentos de percursos, sem subtrair o tempo necessário para a obtenção de um vento favorável à articulação entre os percursos ${ }^{15}$.

\section{As rotas marítimas envolvendo a África}

As onze relações que constam a África nos levam de fato a dois cenários, dependendo se o valor resulta de uma avaliação específica, ou se foi elaborado através da adição de dois segmentos ou mais. Esta diferença de abordagem não resulta inteiramente de uma simplificação burocrática. Ele revela duas formas de navegação: a travessia direta, quando possível, e a navegação "segmentada", mais complexa, articulando itinerários praticados em direções e condições variáveis.

As linhas "diretas" são os mais fáceis para reconstruir

Da África para Gália. Não vamos entrar de novo em detalhes sobre essa rota que já tivemos a ocasião de comentar acima. $\mathrm{O}$ valor especificado corresponde normalmente ao valor do itinerário norte-sul. O itinerário de referência foi uma travesseia direta que passava muito "a oeste da Sicília" (STR., II 5, 8). No verão, as condições eram

sensivelmente comparáveis as do sul das ilhas Baleares. Ao norte do arquipélago, a Tramontana criava situações muito mais difíceis no sentido sul-norte (ARNAUD 2005, pp.153-156).

${ }^{15}$ Sobre a noção de « navegação segmentada », cf. ARNAUD 2005, pp. 97-148. 
Da África para Sicília. A tarifa proporcionalmente muito alta dessa rota exclui que se trata da travesseia entre Lilybaeum (Marsala) ou Marittimo e o Cap-Bon ou Cartago, distâncias avaliadas como correspondentes a um ou dois dias diurnos, dependendo se a travessia é feita diretamente ou por Pantelária (ARNAUD 2005, pp. 160-163). Os dados do Ps.-Scylax (§ 13) e Timóstenes ${ }^{16}$ (AGATHEM., V 22 Müller), colocam entre o cap Cap Pelorus e o cap Lilybaeum distancias correspondentes a dois dias de navegação. As figuras mais aproximadas são as relacionadas com a navegação pelo canal da Sicília entre Siracusa e Cap-Bon (D. S., XX 6, 1-2): do leste para o oeste, muitas vezes é preciso lidar com ventos estabelecidos e correntes contrárias, e no sentido oposto, é o cruzamento ao nível do cap Pachyne que é regularmente problemático. É provavelmente este itinerário, natural para quem adota um ponto de vista oriental, que foi tomado como referência. Isto não implica necessariamente que, quando os autores do édito combinaram esta avaliação a outras, eles tivessem necessariamente em mente essa rota específica, que para eles, é apenas a expressão de um custo máximo entre a Sicília e a África, e não uma rota.

Do Oriente para a África. Do mesmo modo que os custos de Alexandria à África (1. 6) e à Sicília (1. 7) são iguais (10 denários), igualmente, os custos do Oriente à África (1. 14) e à Sicília também são iguais (16 denários). Eles mostram que ambas as vias eram provavelmente em grande parte consideradas comum, e que a estrada a destinação da África não era reputada de passar pela Sicília, uma vez que teria gerado um custo adicional de 6 denários. O aumento de 6 denários entre Alexandria e o Oriente mostra que o itinerário de referência é aquele, atestada pela papirologia17, que na primavera, corria ao longo das costas do Egito e de Cirenaica e, de lá, dirigia-se ou para a Sicília ou para a África, por itinerários que podiam ser em parte comuns até Leptis Magna ou até Malta (ROUGE 1960). A tarifa da relação Alexandria-Roma (1. 1a, 16 denários) se reduz, aliás, à soma Alexandria-Sicília (1. 7, 10 denários) e Roma-Sicília (1. 32). Este não é o caso da rota do Oriente para Roma cujo valor (1. 11, 18 denários) é inferior à soma das rotas do Oriente para a Sicília, e de Roma para a Sicília (16 + 6 = 22 denários), o que indica uma rota específica para a capital, provavelmente um percirso em direção ao norte que chegava em Bruttium.

Da África para Espanha. O custo (1. 28, 8 denários), igual ao da relação com a Ásia, é comparativamente bem elevado, especialmente se comparamos com o preço da relação África-Gália. Uma comparação com 11. 15-17, e sobretudo com XXXV A II, 1. 4, onde a

${ }^{16}$ Mais do que Artémidore, ao contrário da opinião de Stiehle (STIEHLE 1856, p.259, fr.50)

17 Pap.Mich. 420 ; cf. SYNES., Ep. 4. Uma linha sem escala entre a Paraetonium e a Sicília (ROUGÉ 1960) é igualmente atestada (HIER., Vita Hilar. 33-36) 
precisão Tarraconensem foi adicionada, permitindo-nos de reconhecer com uma certa probabilidade Tarraconense. Esta rota, muito rápida no verão para o oeste, desde a Sardenha onde começam os ventos etésios de setor leste é, no entanto, muito difícil de praticar na mesma temporada no sentido oposto. Mais do que o itinerário pela Sardenha, este valor aqui parece corresponder ao itinerário costeiro até o Iol-Césareia e daí para Cartagena.

Da Ásia para a África. A tarifa muito baixa, de 8 denários mostra claramente que esta rota evitava a Sicília (esta tarifada à 6 denários partindo da África). É quase necessariamente uma rota saída da costa oriental de Africa (algum lugar entre Clypea e Leptis Magna) e considerado em condições favoráveis, nas condições de início do verão, no sentido oposto à do enunciado, e sem dúvida destinada não a Éfeso, mas a Rodes ou à Caria.

A quase totalidade das rotas complexas resultantes da adição de dois ou mais itinerários tarifados inclusive no édito passam logicamente pela Sicília, sem que se possa especificar se trata-se sempre da costa oriental da Ilha, aparentemente concernido pela via, comum a todas estes itinerários, da África para a Sicília, eximinada acima.

De Roma para a África. Se, como sugerimos acima, o número que falta a 1. 25 do cap. XXXV é de fato o de 12 denários, parece redutível à soma de dois valores conhecidos, ambos iguais a 6 denários, da África para a Sicília (1. 27) e de Roma para a Sicília (1. 32). Parece excluir a navegação direta pelo oeste da Sicília e a ilha de Marittimo.

Da África para Acaia. A tarifa, de 12 denários, parece particularmente elevada, se comparamos com o custo da relação da Ásia para a África. Esta é obviamente a usada como base de cálculo do custo da relação África para Salônia. Como temos visto acima, parece resultar de dois dados conhecidos: 6 denários da África para a Sicília, e também, correspondente aos 6 dias de viagem de lá para Alfeu. Nada permite determinar se esta tarifa organizava a próxima ou se ela procedia de seu desmembramento artificial.

Da África para Salônia. O édito (1. 26) avalia esta rota em 18 denários, ou seja, uma diferença de 6 denários com a rota África-Acaia, avaliada em 12 denários (1. 30). Esta diferença 6 denários é exatamente a mesma que encontramos entre as rotas de Nicomédia para Acaia (1. 41, 8 denários) e Nicomédia para Acaia (1. 42, 14 denários). Ela nos permite estabelecer que o preço da rota da África para Salônia resultava da adição da tarifa da África para Acaia (12 denários) e do custo de 6 denários, correspondente ao trajeto de Acaia para Salônia, que não é explicitamente formulada nas partes preservadas do édito. Ela se compreende, provavelmente a partir de Alfeu, ponto normal de chegada à Acaia, a partir da Sicília.

Revista Heródoto. Unifesp. Guarulhos, v. 01, n. 01. Março, 2016. p. 438-457. 
De Nicomédia para a África. O valor de 14 denários é igual à soma dos custos das relações Ásia-África (1. 23, 8 denários) e de Nicomédia para Éfeso (1. 39, 6 denários). É aparentemente a única rota complexa a não passar pela Sicília.

Em contrapartida, os custos máximos atribuídos aos três itinerários do Oriente para as Espanhas (11. 15-17), ou seja, 20 denários até Tarraconense, 22 até Bética, e 24 até a Lusitânia, não podem ser reduzidos à soma dos custos atribuídos às relações OrienteÁfrica (16 denários) e África-Espanha (8 denários). Estes itinerários são visivelmente tratados como uma rota própria, em direção à Tarraconense e prorrogado por uma viagem até Lusitânia, em direção da Tarraconaise e prolongada por um périplo até a Lusitânia, como o sugere o crescimento regular dos custos da Tarraconanse à Baetica e de lá para Lusitânia.

O caso da África nos parece bastante exemplar tanto pelo método de trabalho dos autores do édito quanto do potencial documental, limitado, mas não tão ruim como por vezes se pensa, deste documento. Sr. Crawford há trinta anos colocava a questão do método que permitiu a Diocleciano à fixação de preços máximos válidos em todas as partes do império, e supunha que seus serviços teriam utilisado o que eles tinham em mãos (CRAWFORD 1975, p.278). Para nos restrigirmos ao objeto que nos interessou, a hipótese de utilização parcial de um documento anterior, grego, de origem levantina, caminha claramente neste sentido. Ela é confortada por vários detalhes que apareceram durante este estudo. Em primeiro lugar o ponto de vista geralmente oriental optado para fixar a tarifa, quer se tratasse da tarifação elevada da rota da Africa para a Sicila, que terminou por condicionar a tarifação da rota ÁfricaRoma, quer se tratasse da super representação do Oriente no édito. Essa é geralmente a propensão de algumas linhas de transporte, evitando o canal da Sicília em favor do canal de Messina. É enfim um fato, de que as rotas cujo os preços são fixados com as adicões as mais artificiais são aquelas que concernem a Salônia e a Nicomédia. Poderia ter existido antes de Diocleciano uma tentativa de regulação de preços do naulum de cuja qual teria inspirado o fundador da Tetrarquia.

A simplicidade do algoritmo usado para o cálculo dos custos - talvez emprestado ao modelo do édito - poderia aparecer como um compromisso aceitável entre a realidade e artificialidade, entre a particularidade de cada linha de negócio, com seus itinerários sazonais e a necessidade de uma lista sucinta, ampla o suficiente para dar uma visão global da extensão do mar reaberto ao comércio pela paz, e restrita o suficiente para continuar a ser aplicável. É uma África cortada de sua rede de relações de proximidade e reintegrada nas relações de longa distância que, sozinha, toma em condideração o edital. As únicas linhas tafifadas são aquelas que condicionavam a unidade econômica do império, conectando seus pontos mais distantes. 
As lacunas de adições de Aphrodisias, às quais gostaríamos de conhecer a data exata, seriam talvez capazes alterar um pouco visão das coisas, e a integração dos destinos intermediários, como a Sardenha e Gênova, a estas adições, mostra tanto a vontade de aperfeiçoar o Édito e a satisfação geral que se anexava, do ponto do governo central, à implementação das relações de tarifação. No estado de nosso conhecimento, eles também mostram um reequilíbrio em favor do Ocidente, em que a África ocupa um lugar fundamental. Os custos proporcionalmente muito baixos de relações entre a África e o resto do mundo (com exceção da Acaia) enfatizam o seu papel como um centro de comércio do Mediterrâneo e do seu lugar privilegiado no espaço-tempo da navegação no Mediterrâneo.

\section{Referências bibliográficas}

A bibliografia deste artigo integra um conjunto de referências de todo o volume no qual ele foi publicado. Sugerimos aos leitores consulta à publicação original, disponível na página pessoal de Pascal Arnaud no academia.edu 